\title{
Knowledge and attitude of patients undergoing lower extremity amputation at RK Khan Hospital, Chatsworth
}

\author{
B Olotu, ${ }^{1}$ F Anderson ${ }^{2}$ \\ ${ }^{1}$ Department of General Surgery, Nelson R. Mandela Medical School, University of KwaZulu-Natal, South Africa \\ ${ }^{2}$ Department of Hepato-Biliary Surgery, Inkosi Albert Luthuli Central Hospital, South Africa
}

Corresponding author: Boladele Olotu (bolaolootu@yahoo.com)

\begin{abstract}
Background: Amputation is one of the oldest and most commonly performed surgical procedures.
Objective: To review the knowledge and attitude of patients undergoing lower extremity amputations and describe the associated causative factors.

Methodology: A questionnaire-based prospective study assessing patients either preoperatively or immediately postoperatively regarding their knowledge and attitudes toward lower extremity amputation was conducted between November 2016 and April 2017. Extracted data was captured into an Excel spreadsheet and imported into SPSS for statistical analysis.

Results: Sixty-three amputations were performed with males accounting for $56 \%$ of the study population. The majority were in the age group of 61-70 years (33\%). The commonest indication for amputation was complication of diabetes mellitus or diabetes foot sepsis $(65 \%)$. Below-knee amputation (BKA) was the most frequently performed procedure and accounted for $56 \%$ of all amputations. Seventy per cent of the participants had formal education and $60 \%$ knew that their condition could lead to an amputation, but only approximately $10 \%$ visited the foot clinic before their major amputation despite the service being available at RK Khan Hospital. Smoking was the commonest habit associated with amputation.

Conclusion: Complications of diabetic mellitus are the most common indication for lower extremity amputation. A high percentage of patients knew their co-morbid condition could lead to limb loss but failed to seek medical assistance until late in their disease process.
\end{abstract}

Keywords: amputation, indication, knowledge, attitude, lower extremities.

S Afr J Surg 2019;57(4)

http://dx.doi.org/10.17159/2078-5151/2019/v57n4a2920

\section{Introduction}

Lower extremity amputation (LEA) is an ancient surgical procedure performed worldwide and is defined as removal of part of, or a whole limb. ${ }^{1}$ In the United States, 30 000-40 000 amputations are performed annually. In 2005, there were an estimated 1.6 million amputees worldwide. This figure is expected to rise to 3.6 million by $2050 .^{2}$ Presently there is no data on the incidence and prevalence of low er extremity amputation in South Africa.

The indications for LEA vary. Diabetic complications, peripheral vascular disease, trauma, malignancy, infection and congenital limb defects are some of the conditions that may result in lower limb amputation. In high income countries (HICs), peripheral vascular disease ranked first as the cause of amputation while trauma, infection, complications of diabetes mellitus and malignancy are indications for amputation in low- to middle-income countries (LMICs). ${ }^{3,4}$ In a study conducted in four public hospitals in Cape town, $72.3 \%$ of LEAs were in people with diabetes mellitus. ${ }^{3}$

Patients undergoing LEA have considerable risk factors for chronic medical conditions such as hypertension (77\%), hypercholesterolemia (29\%), raised serum creatinine $(35 \%)$ and/or history of smoking $(82 \%) .{ }^{5}$ Hypertension is a major risk factor for lower extremity amputation if untreated. ${ }^{6}$ In type 2 diabetes mellitus patients, hypertension is part of the syndrome including glucose intolerance, insulin resistance, obesity, and dyslipidaemia, which are contributing factors to neuro-ischaemic ulcers. ${ }^{7}$

With the rising number of amputations performed in South African hospitals and the lack of a national data registry, it is imperative that studies are conducted to determine the knowledge and attitude of patients undergoing this procedure and to determine the indications for amputation. This should be seen within the broader framework of the considerable psychological, economic and societal impact 
lower extremity amputation operations have on society. There is a dearth of literature on knowledge and attitude of patients undergoing LEA. Most of the published work expands on the characteristics of amputations such as indications, the biomechanics of amputees and prosthesis requirement. These studies have not specifically addressed the knowledge and attitude of patients receiving lower extremity amputation as surgical treatment for their condition.

The aim of the study was to determine the knowledge and attitude of patients undergoing lower extremity amputation at RK Khan Hospital, a level 2 regional hospital in Durban.

\section{Table 1. Demographic and clinical characteristics}

\begin{tabular}{|c|c|}
\hline & $N=63(100 \%)$ \\
\hline \multicolumn{2}{|l|}{ Age } \\
\hline $30-40$ & $3(4.8)$ \\
\hline $41-50$ & $12(19.0)$ \\
\hline $51-60$ & $17(27.0)$ \\
\hline $61-70$ & $21(33.3)$ \\
\hline$>70$ & $10(15.9)$ \\
\hline \multicolumn{2}{|l|}{ Sex } \\
\hline Male & $35(55.6)$ \\
\hline Female & $28(44.4)$ \\
\hline \multicolumn{2}{|l|}{ Ethnicity } \\
\hline Black & $38(60.3)$ \\
\hline Indian & $16(25.4)$ \\
\hline White & $8(12.7)$ \\
\hline Coloured & $1(1.6)$ \\
\hline \multicolumn{2}{|l|}{ Education } \\
\hline Formal & $44(69.8)$ \\
\hline Non-formal & $19(30.2)$ \\
\hline \multicolumn{2}{|l|}{ Employment } \\
\hline Employed & $20(31.7)$ \\
\hline Unemployed & $43(68.3)$ \\
\hline \multicolumn{2}{|l|}{ Hypertension } \\
\hline Yes & $51(81.0)$ \\
\hline No & $12(19.0)$ \\
\hline \multicolumn{2}{|c|}{ Diabetes mellitus } \\
\hline Yes & $54(85.7)$ \\
\hline No & $9(14.3)$ \\
\hline \multicolumn{2}{|l|}{ Obesity } \\
\hline Yes & $16(25.4)$ \\
\hline No & $47(74.6)$ \\
\hline \multicolumn{2}{|l|}{ Asthma } \\
\hline Yes & $3(4.8)$ \\
\hline No & $60(95.2)$ \\
\hline \multicolumn{2}{|c|}{ Hypercholesterolemia } \\
\hline Yes & $29(46.0)$ \\
\hline No & $34(54.0)$ \\
\hline \multicolumn{2}{|l|}{ PVD } \\
\hline Yes & $15(23.8)$ \\
\hline No & $48(76.2)$ \\
\hline \multicolumn{2}{|l|}{ RVD } \\
\hline Positive & $15(23.8)$ \\
\hline Negative & $48(76.2)$ \\
\hline \multicolumn{2}{|l|}{ Hb level } \\
\hline$>7$ & $57(90.5)$ \\
\hline$<7$ & $6(9.5)$ \\
\hline
\end{tabular}

\section{Methodology}

The study was conducted over a six-month period between November 2016 to April 2017 at RK Khan Hospital, a level 2 regional hospital with a general surgical service, and one of the University of KwaZulu-Natal training hospitals in Durban. All patients 18 years and older who consented to an amputation during the study period were included. This prospective study used a questionnaire to determine the knowledge and attitude of patients undergoing LEA at RK Khan Hospital and chartreview of clinical data to enable calculation of the Wagner Score for disease severity used to determine the level and type of amputation. Extracted data was captured onto an Excel spreadsheet and imported into SPSS version 25 for statistical analysis, chi-square was used to determine association between variables at a $\mathrm{p}$-value $<0.05$.

\section{Results}

After chart review to eliminate duplication, a total of sixtythree participants consented to enrolment in the study.

\section{Demographic and clinical characteristics of LEA patients (Table 1)}

The mean age was 58.9 years (range $30->70$ years). The highest number of LEA was performed in patients between the ages of $61-70$ years $(33.3 \%)$, closely followed by the age group 50-60 years (27\%). Male gender predominated (56\%). Most of the participants were Blacks $(60.3 \%)$, followed by Indians $(25.4 \%)$. The majority of participants had formal education $(70 \%)$ while $68 \%$ were unemployed. Medical comorbidities found from the study were hypertension $(81 \%)$, diabetes mellitus $(85.7 \%)$, obesity $(25.4 \%)$, asthma $(4.8 \%)$, hypercholesterolemia (46\%), retro-viral disease (RVD) $(23.8 \%)$ and haemoglobin $(\mathrm{Hb})$ level (> $7 \mathrm{~g} / \mathrm{dl})(90.5 \%)$.

\section{Operation performed (Table 2)}

The most frequently performed LEA was a BKA, accounting for $56 \%$ of amputations. The most common part of the limb involved was below the ankle (67\%). Most participants presented with Wagner grade 2 and 3, 39.7\% and 23.8\% respectively.

\begin{tabular}{lc}
\multicolumn{2}{l}{ Table 2. Frequently performed lower extremity amputation } \\
\hline \multicolumn{2}{l}{$\mathbf{N}=\mathbf{6 3}(\mathbf{1 0 0 \% )}$} \\
\hline Type of procedure & $11(17.5)$ \\
Toectomy & $6(9.5)$ \\
Trans-metatarsal amputation & $35(55.6)$ \\
Below-knee amputation & $11(17.5)$ \\
Above-knee amputation & \\
Part of the limb involved & $42(66.7)$ \\
Below the ankle & $20(31.7)$ \\
Above the ankle & \\
Wagner & $4(6.4)$ \\
0 & $13(20.6)$ \\
1 & $25(39.7)$ \\
2 & $15(23.8)$ \\
3 & $3(4.8)$ \\
4 & $3(4.8)$
\end{tabular}


Table 3. Indication for lower extremity amputation

\begin{tabular}{lc}
\hline & $\mathbf{N}=\mathbf{6 3}(\mathbf{1 0 0} \%)$ \\
\hline Indication for amputation & $41(65.1)$ \\
Diabetes mellitus & $21(33.3)$ \\
PVD & $1(1.6)$ \\
Trauma & $48(76.2)$ \\
Total number of operations in the same admission \\
1 & $12(19)$ \\
2 & $3(4.8)$ \\
3 & \\
Disease duration & $9(14.3)$ \\
1 week & $26(41.3)$ \\
2 weeks & $28(44.4)$ \\
More than 2 weeks &
\end{tabular}

\section{Indication for amputation (Table 3)}

Complications of diabetes mellitus were the commonest indications for LEA (65\%), followed by PVD (33\%). A single procedure in the same admission was performed in $76 \%$ of participants. Fourteen per cent of the participants presented within a week of the disease process while $41 \%$ and $44 \%$ of the participants presented at two weeks and later, respectively

\section{Knowledge deficiency and attitude that predispose patients to LEA (Table 4)}

In determining the knowledge deficiency and attitude that predispose patients to lower extremity limb amputation, (44\%) of the participants smoked. Most of the participants $(60 \%)$ were aware that their condition could lead to an amputation although $83 \%$ did not know about the existence of a foot clinic, and only $6 \%$ attended the foot clinic in one year.

\section{Statistical analysis (Table 5)}

Male gender was significantly associated with smoking; white ethnicity, formal education and current employment were significantly associated with patient knowledge that their condition could lead to amputation; white ethnicity and formal education were significantly associated with patients who heard about the foot clinic and those who had formal education have association with diabetes.

\section{Discussion}

Our study showed that $44.4 \%$ of patients were smokers and male patients were more likely to smoke than female patients. Previous studies have shown that smoking was neither related to amputation risk ${ }^{8}$ nor had an influence on diabetic foot amputation..$^{9}$ Our study indicated that smoking was not significantly associated with indications for lower extremity amputation, however, we demonstrated an association between smoking and diabetes mellitus $(33.3 \%$ v. $11.3 \%$; $<<0.05)$. This finding is consistent with studies that have demonstrated smoking as a risk factor in diabetic foot amputation. ${ }^{10-12}$ Our study also confirmed that complications of diabetes mellitus ranked highest as the commonest indications for lower extremity amputation, followed by peripheral vascular disease. Similar trends were seen in studies conducted on
Table 4. Knowledge deficiencies and attitude that predisposed patients to LEA

\begin{tabular}{|c|c|}
\hline & $N=63(100 \%)$ \\
\hline \multicolumn{2}{|l|}{ Smoking } \\
\hline Yes & $28(44.4)$ \\
\hline No & $35(55.6)$ \\
\hline \multicolumn{2}{|l|}{ Fungi infection } \\
\hline Yes & $4(6.3)$ \\
\hline No & $59(93.7)$ \\
\hline \multicolumn{2}{|l|}{ Dry skin } \\
\hline Yes & $5(7.9)$ \\
\hline No & $58(92.1)$ \\
\hline \multicolumn{2}{|l|}{ Nail abnormality } \\
\hline Yes & $2(3.2)$ \\
\hline No & $61(96.8)$ \\
\hline \multicolumn{2}{|l|}{ Callus } \\
\hline Yes & $3(4.8)$ \\
\hline No & $60(95.2)$ \\
\hline \multicolumn{2}{|l|}{ Alcohol } \\
\hline Yes & $11(17.5)$ \\
\hline No & $52(82.5)$ \\
\hline \multicolumn{2}{|c|}{ Know that condition could lead to amputation } \\
\hline Yes & $38(60.3)$ \\
\hline No & $25(39.7)$ \\
\hline \multicolumn{2}{|l|}{ Duration known } \\
\hline$<1$ month & $4(6.3)$ \\
\hline$>1$ month & $34(54.0)$ \\
\hline None & $25(39.7)$ \\
\hline \multicolumn{2}{|c|}{ Heard about foot clinic } \\
\hline Yes & $11(17.5)$ \\
\hline No & $52(82.5)$ \\
\hline \multicolumn{2}{|c|}{ Clinic attendance in a year } \\
\hline Once & $1(1.6)$ \\
\hline More than 3 times & $3(4.8)$ \\
\hline None & $59(93.7)$ \\
\hline \multicolumn{2}{|l|}{ Foot inspection } \\
\hline Yes & $56(88.9)$ \\
\hline No & $7(11.1)$ \\
\hline \multicolumn{2}{|l|}{ Podiatrist visit } \\
\hline Yes & $6(9.5)$ \\
\hline No & $57(90.5)$ \\
\hline
\end{tabular}

major amputation., ${ }^{3,13}$ LEA is twice as common in diabetic patients compared to non-diabetic patients. ${ }^{14}$

Poor foot care is a risk factor for developing diabetic foot sepsis which may later require an amputation. The majority of participants did not present with foot related problems such as fungal infection $(6.3 \%)$, dry skin $(7.9 \%)$, nail abnormality $(3.2 \%)$ and callus $(4.8 \%)$ before amputation. This is in contrast with a study conducted among diabetic patient in Jordan which reported fungal infection, foot dryness, toe nail disorder and corns in their patients to be $29 \%, 56.7 \%, 34.6 \%$ and $25.7 \%$ respectively. ${ }^{15}$ Our study found that the majority of participants (89\%) inspected their feet regularly. This finding is consistent with a study conducted in Saudi Arabia $(79.5 \%)^{16}$ but is in contrast with a Jordanian study ${ }^{15}$ where only $4.9 \%$ of diabetic patients inspected their feet. 
Table 5. Cross tabulation

\begin{tabular}{|c|c|c|c|c|c|c|c|c|c|c|c|c|c|}
\hline & \multicolumn{2}{|c|}{ Smoking } & \multirow[t]{2}{*}{$\begin{array}{c}\text { Chi- } \\
\text { square } \\
\text { p-value }\end{array}$} & \multicolumn{2}{|c|}{$\begin{array}{c}\text { Know that } \\
\text { condition can lead } \\
\text { to amputation }\end{array}$} & \multirow[t]{2}{*}{$\begin{array}{c}\text { Chi- } \\
\text { square } \\
\text { p-value }\end{array}$} & \multicolumn{2}{|c|}{$\begin{array}{l}\text { Heard about foot } \\
\text { clinic }\end{array}$} & \multirow[t]{2}{*}{$\begin{array}{c}\text { Chi- } \\
\text { square } \\
\text { p-value }\end{array}$} & \multicolumn{3}{|c|}{ Indication for amputation } & \multirow[t]{2}{*}{$\begin{array}{c}\text { Chi- } \\
\text { square } \\
\text { p-value } \\
\end{array}$} \\
\hline & Yes & No & & Yes & No & & Yes & No & & Diabetes & PVD & Trauma & \\
\hline \multicolumn{14}{|l|}{ Age n (\%) } \\
\hline $30-40$ & $1(1.6)$ & $2(3.2)$ & & $2(3.2)$ & $1(1.6)$ & & $1(1.6)$ & $2(3.2)$ & & $3(4.8)$ & $0(0)$ & $0(0)$ & \\
\hline $41-50$ & $4(6.3)$ & $8(12.7)$ & & $8(12.7)$ & $4(6.4)$ & & $0(0)$ & $12(19.1)$ & & $6(9.5)$ & $6(9.5)$ & $0(0)$ & \\
\hline $51-60$ & $9(14.3)$ & $8(12.7)$ & & $14(22.2)$ & $3(4.8)$ & & $5(7.9)$ & $12(19.1)$ & & $13(20.6)$ & $4(6.4)$ & $0(0)$ & \\
\hline $61-70$ & $11(17.5)$ & $10(15.9)$ & & $10(15.9)$ & $11(17.5)$ & & $3(4.8)$ & $18(28.6)$ & & $15(23.8)$ & $5(7.9)$ & $1(1.6)$ & \\
\hline $70+$ & $3(4.8)$ & $7(11.1)$ & 0.622 & $4(6.4)$ & $6(9.5)$ & 0.145 & $2(3.2)$ & $8(12.7)$ & 0.294 & $4(6.4)$ & $6(9.5)$ & $0(0)$ & 0.293 \\
\hline \multicolumn{14}{|l|}{$\overline{\operatorname{Sex}}$} \\
\hline Male & $22(34.9)$ & $13(20.6)$ & & $21(33.3)$ & $14(22.2)$ & & $9(14.3)$ & $26(41.3)$ & & $24(38.1)$ & $14(22.2)$ & $0(0)$ & \\
\hline Female & $6(9.5)$ & $22(34.9)$ & 0.001 & $17(27.0)$ & $11(17.5)$ & 0.954 & $2(3.2)$ & $26(41.3)$ & 0.054 & $20(31.8)$ & $7(11.1)$ & $1(1.6)$ & 0.271 \\
\hline \multicolumn{14}{|l|}{ Ethnicity } \\
\hline Black & $15(24.2)$ & $23(37.1)$ & & $18(29.0)$ & $20(32.3)$ & & $2(3.2)$ & $36(58.1)$ & & $23(37.1)$ & $14(22.6)$ & $1(1.6)$ & \\
\hline Indian & $8(12.9)$ & $7(11.3)$ & & $10(16.1)$ & $5(8.1)$ & & $4(6.5)$ & $11(17.7)$ & & $10(16.1)$ & $5(8.1)$ & $0(0)$ & \\
\hline White & $4(6.5)$ & $4(6.5)$ & & $8(12.9)$ & $0(0)$ & & $5(8.1)$ & $3(4.8)$ & & $7(11.3)$ & $1(1.6)$ & $0(0)$ & \\
\hline Coloured & $0(0)$ & $1(1.6)$ & 0.626 & $1(1.6)$ & $0(0)$ & 0.032 & $0(0)$ & $1(1.6)$ & 0.001 & $0(0)$ & $1(1.6)$ & $0(0)$ & 0.608 \\
\hline \multicolumn{14}{|l|}{ Education } \\
\hline Formal & $21(33.9)$ & $23(37.1)$ & & $33(53.2)$ & $11(17.7)$ & & $11(17.7)$ & $33(53.2)$ & & $33(53.2)$ & $11(17.7)$ & $0(0)$ & \\
\hline Non-formal & $6(9.7)$ & $12(19.4)$ & 0.299 & $5(8.1)$ & $13(21.0)$ & 0.001 & $0(0)$ & $18(29.0)$ & 0.019 & $8(12.9)$ & $9(14.5)$ & $1(1.6)$ & 0.035 \\
\hline \multicolumn{14}{|l|}{ Employment } \\
\hline Employed & $8(12.7)$ & $12(19.0)$ & & $16(25.4)$ & $4(6.3)$ & & $6(9.5)$ & $14(22.2)$ & & $15(23.8)$ & $5(7.9)$ & $0(0)$ & \\
\hline Unemployed & $20(31.7)$ & $23(36.5)$ & 0.628 & $22(34.9)$ & $21(33.3)$ & 0.029 & $5(7.9)$ & $38(60.3)$ & 0.074 & $26(41.3)$ & $16(25.4)$ & $1(1.6)$ & 0.468 \\
\hline
\end{tabular}

The majority of participants in this study were Black $(60.3 \%)$ notwithstanding the study centre located in an Indian community. Black patients were significantly more at risk of amputation than other ethnic groups in our study. We also found that White patients, patients with a formal education and those who were employed were more likely to know that their condition could lead to an amputation. The majority of participants $(54.0 \%)$ knew that their condition could lead to limb loss if the process was present for more than a month. Majority of the LEA could be delayed or prevented by more effective patient education and medical supervision during clinic attendance. ${ }^{17}$ Our study demonstrated that most of the participants $(44.4 \%)$ presented late in their disease process.

Studies have shown that education ${ }^{18}$ and socioeconomic status $^{19}$ are significantly associated with foot care knowledge among diabetic patients. ${ }^{20}$ Our study confirmed that the majority of patients had a formal education (70\%), however only $31.7 \%$ of all patients were employed. Socioeconomic status is an amputation risk in patients with diabetes; those in a lower socioeconomic level are more likely to develop risk factors for amputations. ${ }^{19}$ Most of the patients $(82.5 \%)$ were not aware of the existence of a diabetic foot clinic. Those who heard about the clinic $(17.5 \%)$ had a formal education and only $6.3 \%$ visited the clinic before their amputation. These findings are similar to those reported in a study conducted in Jordan, where only $19.3 \%$ had heard about a foot specialist and $7.1 \%$ had visited the clinic..$^{15}$ Knowledge of appropriate foot care is positively influenced by patient education, ${ }^{18}$ amputation rate was significantly lower among patients who were exposed to foot care education than their counterparts. ${ }^{17}$
Appropriate foot care reduces the risk of foot ulceration and amputation in diabetic patients. ${ }^{18}$ Foot care education and creating awareness on the availability of foot care clinics form the cornerstone in the at-risk population of society.

\section{Conclusion}

Our study showed that participants were knowledgeable about the predisposing factors for amputation, but poor foot clinic attendance and poor attitude regarding foot care increased their chances of having an amputation. We propose ongoing health education at primary health care centres as well as informing diabetic patients of the availability of foot clinics and encouraging regular visits for professional advice on foot care.

The project was approved by UKZN Biomedical Research Ethics Committee (BE078/16).

\section{Limitations}

The study was limited in that it was conducted in Chatsworth, an Indian suburb which may not be a true representation of the general South African population. It was underpowered in numbers; a more robust prospective study needs to be conducted to validate the findings of this study.

\section{Conflict of interest}

We declare there is no conflict of interest in this study.

\section{Orcid}

B Olotu http://orcid.org/0000-0001-8806-3548 


\section{REFERENCES}

1. Robinson KP. Historical aspects of amputation. Ann R Coll Surg Engl. 1991;73(3):134-6.

2. Ziegler-Graham K, MacKenzie EJ, Ephraim PL, Travison TG, Brookmeyer R. Estimating the prevalence of limb loss in the United States: 2005 to 2050. Arch Phys Med Rehabil. 2008;89(3):422-9.

3. Dunbar GL, Hellenberg DA, Levitt N. Diabetes mellitus and non-traumatic lower extremity amputations in four public sector hospitals in Cape Town, South Africa, during 2009 and 2010. S Afr Med J. 2015;105(12).

4. Wong M. Lower extremity amputation in Hong Kong. Hong Kong Med J. 2005;11(3):147-52.

5. Lim TS, Finlayson A, Thorpe JM, Sieunarine K, Mwipatayi BP, Brady A, et al. Outcomes of a contemporary amputation series. ANZ J Surg. 2006;76(5):300-5.

6. Pemayun TGD, Naibaho RM, Novitasari D, Amin N, Minuljo TT. Risk factors for lower extremity amputation in patients with diabetic foot ulcers: a hospital-based case-control study. Diabet Foot Ankle. 2015;6(1):29629.

7. Krader C. American Diabetes Association. Diabetes clinical practice recommendations focus attention on individualization of care. J Med Econ. 2014;91(16):22-.

8. Selby JV, Zhang D. Risk factors for lower extremity amputation in persons with diabetes. Diabetes Care. 1995;18(4):509-16.

9. Stewart C. The influence of smoking on the level of lower limb amputation. Prosthet Orthot Int. 1987;11(3):113-6.

10. Liu M, Zhang W, Yan Z, Yuan X. Smoking increases the risk of diabetic foot amputation: A meta-analysis. Exp Ther Med. 2018;15(2):1680-5.

11. Jiang Y, Ran X, Jia L, Yang C, Wang P, Ma J, et al. Epidemiology of type 2 diabetic foot problems and predictive factors for amputation in China. Int J Low Extrem Wounds. 2015;14(1):1927.
12. Yesil S, Akinci B, Yener S, Bayraktar F, Karabay O, Havitcioglu $\mathrm{H}$, et al. Predictors of amputation in diabetics with foot ulcer: single center experience in a large Turkish cohort. Hormones. 2009;8(4):286-95.

13. Chalya PL, Mabula JB, Dass RM, Ngayomela IH, Chandika $\mathrm{AB}$, Mbelenge $\mathrm{N}$, et al. Major limb amputations: A tertiary hospital experience in northwestern Tanzania. J Orthop Surg Res. 2012;7(1):18.

14. Gregg EW, Sorlie P, Paulose-Ram R, Gu Q, Eberhardt MS, Wolz M, et al. Prevalence of lower-extremity disease in the US adult population $\geq 40$ years of age with and without diabetes: 1999-2000 national health and nutrition examination survey. Diabetes Care. 2004;27(7):1591-7.

15. Abu-Qamar MeZ. Diabetic foot examination: findings of a screening survey performed in Jordan. European Diabetes Nursing. 2012;9(3):75-80.

16. Al-Hariri MT, Al-Enazi AS, Alshammari DM, Bahamdan AS, Al-Khtani SM, Al-Abdulwahab AA. Descriptive study on the knowledge, attitudes and practices regarding the diabetic foot. Journal of Taibah University Medical Sciences. 2017;12(6):4926.

17. Al-Wahbi AM. Impact of a diabetic foot care education program on lower limb amputation rate. Vasc Health Risk Manag. 2010;6:923-34.

18. Singh N, Armstrong DG, Lipsky BA. Preventing Foot Ulcers in Patients With Diabetes. JAMA. 2005;293(2):217-28.

19. Venermo M, Manderbacka K, Ikonen T, Keskimäki I, Winell K, Sund R. Amputations and socioeconomic position among persons with diabetes mellitus, a population-based register study. BMJ Open. 2013;3(4):e002395.

20. Desalu O, Salawu F, Jimoh A, Adekoya A, Busari O, Olokoba A. Diabetic foot care: self reported knowledge and practice among patients attending three tertiary hospital in Nigeria. Ghana Med J. 2011;45(2). 